\title{
Fundamental Mechanisms of Interface Roughness
}

Award No. DE-FG02-03ER46032

Final Report

October 1, 2003 - September 30, 2007

Randall L. Headrick

University of Vermont, Burlington VT 05405

\section{University of Vermont Personnel}

\author{
R.L. Headrick, PI (8\%) \\ Michael Rushford, Undergraduate Research Assistant (Summer 2004) \\ Greggory Carpenter, Undergraduate Research Assistant (Fall 2004) \\ Zhangcheng Xu, Postdoctoral Research Associate (April, 2004 - September 2004) \\ Yiping Wang, Postdoctoral Research Associate (October, 2004 - March 2006) \\ Hua Zhou, Graduate Research Assistant (April 2007 - September 2007)
}

\section{Significant Findings/Events/accomplishments}

Publication quality results were obtained for several experiments and materials systems including:

(i) Patterning and smoothening of sapphire surfaces by energetic $\mathrm{Ar}^{+}$ions. Grazing Incidence Small Angle X-ray Scattering (GISAXS) experiments were performed in the system at the National Synchrotron Light Source (NSLS) X21 beamline. $\mathrm{Ar}^{+}$ions in the energy range from $300 \mathrm{eV}$ to $1000 \mathrm{eV}$ were used to produce ripples on the surfaces of singlecrystal sapphire. It was found that the ripple wavelength varies strongly with the angle of incidence of the ions, which increase significantly as the angle from normal is varied from $55^{\circ}$ to $35^{\circ}$. A smooth region was found for ion incidence less than $35^{\circ}$ away from normal incidence. In this region a strong smoothening mechanism with strength proportional to the second derivative of the height of the surface $\left(\propto \nabla^{2} h\right)$ was found to be responsible for the effect. The discovery of this phase transition between stable and unstable regimes as the angle of incidence is varied has also stimulated new work by other groups in the field.

(ii) Growth of Ge quantum dots on $\mathrm{Si}(100)$ and (111). We discovered the formation of quantum wires on $4^{\circ}$ misoriented $\mathrm{Si}(111)$ using real-time GISAXS during the deposition of Ge. The results represent the first time-resolved GISAXS study of Ge quantum dot formation.

(iii) Sputter deposition of amorphous thin films and multilayers composed of $\mathrm{WSi}_{2}$ and $\mathrm{Si}$. $\mathrm{WSi}_{2} / \mathrm{Si}$ multilayers are of current interest because the multilayer deposition facility at the Advanced Photon Source is presently making Multilayer Laue Lenses (MLLs) from $\mathrm{WSi}_{2} / \mathrm{Si}$ multilayers. This appears to be the leading approach to produced low nanometer scale 
focused x-ray beams. Our in-situ GISAXS experiments reveal fundamental roughening and smoothing phenomena on surfaces during film deposition. The main results of this work is that the $\mathrm{WSi}_{2}$ layers actually become smoother during deposition due to the smoothening effect of energetic particles in the sputter deposition process.

Instrumentation accomplishments include the commissioning of an in-situ growth/x-ray chamber at the NSLS X21A beamline at the beginning of this project. In addition, we have completed several significant instrumentation upgrades either supported directly by this project (dual-gun magnetron sputtering source), or instrumental to the success of this project and future research (acquisition of a new laser for laser deposition studies). We have also collaborated with the detector group at the NSLS during the development of a linear array detector that has been used very successfully for time-resolved x-ray scattering studies.

\section{Students and postdoctoral associates supported by the project:}

\section{Undergraduates supported by DOE}

Two undergraduate students worked on computer simulations of epitaxial growth by pulsed laser deposition. We have performed atomistic simulations of $\mathrm{Cu}$ deposition on $\mathrm{Cu}(111)$ in order to understand the mechanisms of epitaxial growth during PLD. The results have been helpful in planning future research in this area. Mr. Rushford has subsequently pursued a graduate degree in Physics.

\section{Postdoctoral Fellows supported by DOE}

One postdoctoral associate has worked on Ge quantum dots on Si. (Zhangcheng Xu). A second postdoctoral associate, Yiping Wang, participated in experiments on the sputter deposition of $\mathrm{WSi}_{2} / \mathrm{Si}$ mutilayers. Both postdoctoral students have subsequently taken faculty positions at universities in China.

\section{Graduate Students supported by DOE}

One graduate student, Hua Zhou, has worked on patterning and smoothening of sapphire surfaces. His Ph.D. thesis was on work done as part of this project and he received his degree in October 2007. Subsequently, he was hired as a postdoctoral research associate at Brookhaven National Laboratory.

\section{Publications}

1) "Interface roughness evolution in sputtered $\mathrm{WSi}_{2} / \mathrm{Si}$ multilayers," Y.P. Wang, $\mathrm{H}$. Zhou, L. Zhou, R.L. Headrick, A.T. Macrander, and A.S. Ozcan, J. Appl. Phys. 101, 023503 (January 2007).

2) "Wavelength tunability of ion-bombardment induced ripples on sapphire," H. Zhou, Y.P. Wang, L. Zhou, R.L. Headrick, A.S. Ozcan, Y.Y. Wang, G. Ozaydin, K.F. Ludwig, Jr., and D.P. Siddons, Phys. Rev. B, 75, 155416 (April 2007). 
3) "Self-organized growth of microsized Ge wires on Si (111) surfaces," Z.C. Xu, Y.T. Zhang, R.L. Headrick, H. Zhou, L. Zhou, and T. Fukamachi, Phys. Rev. B 75, 233310 (June 2007)

4) "Mechanisms of pattern formation and smoothing induced by ion-beam erosion," $\mathrm{H}$. Zhou, L. Zhou, G. Ozaydin, K.F. Ludwig, Jr., and R.L. Headrick, Phys. Rev. B 78, 165404 (October 2008).

5) "Ion beam erosion induced self organized patterns on sapphire", H. Zhou, Ph.D. Thesis, University of Vermont (October 2007).

\section{Presentations}

1) "Kinetic Monte Carlo simulations of pulsed growth," M. Rushford, presented at the April 2003 Meeting of the American Physical Society, session B14 (Society of Physics Students), Baltimore MD. Contributed Oral Presentation.

2) "In-situ study Co pattern formation by synchrotron x-ray scattering and atomic force microscopy,” H. Zhou, R.L. Headrick, A. Ozcan, G. Ozaydin, Y. Wang, J. Hotchkiss, K. Ludwig, C. Eddy, Focus Session: Mechanical Properties of Nanostructured Thin Films and Coatings I, American Physical Society meeting Monreal, Can., March 2004. Contributed Oral Presentation.

3) "Investigation of the interface structure in sputtered $\mathrm{WSi}_{2} / \mathrm{Si}$ multilayers by in-situ synchrotron X-ray scattering," Yiping Wang, Hua Zhou, Lan Zhou, R.L. Headrick, A.T. Macrander and K.F. Ludwig Jr. Bull. Am. Phys. Soc., 51, No. 1, 885 (2006). Focus Session: Alloy and Interface Composition. March Meeting of the American Physical Society, Baltimore MD. March 13-17, 2006. Contributed Oral Presentation.

4) "Wavelength Tunability of Ion-bombardment Induced Surface Ripples on Sapphire," Hua Zhou, Lan Zhou, Yi-Ping Wang, R.L. Headrick, A.S. Ozcan, Yi-Yi Wang, Gozde Ozaydin, K.F. Ludwig Jr. and D.P. Siddons. Bull. Am. Phys. Soc., 51, No. 1, 294 (2006). Session: Morphological Evolution and Instabilities. March Meeting of the American Physical Society, Baltimore MD. March 13-17, 2006. Contributed Oral Presentation.

5) "Ion-irradiation Induced Surface Ripples on Sapphire," Hua Zhou, Lan Zhou, Yi-Ping Wang, R.L. Headrick, A.S. Ozcan, Yi-Yi Wang, Gozde Ozaydin, K.F. Ludwig Jr. and D.P. Siddons. Symposium on Self Assembly of Nanostructures Aided by Ion- or Photon-Beam Irradiation. Materials Research Society Fall Meeting, Boston, MA. November 27 - December 1, 2006. Contributed Oral Presentation.

6) "Real-time X-ray Scattering Studies of Surface Morphology Evolution during the Sputter Deposition of $\mathrm{WSi}_{2}$ Amorphous Films," L. Zhou, H. Zhou, R. Headrick, A. Macrander, N. Bouet, and K. Ludwig. Symposium on Materials in Transition-Insights from Synchrotron and Neutron Sources, Materials Research Society Fall Meeting, Boston, MA. November 26 - 30, 2007. Contributed Oral Presentation. 
7) "Quantitative Determination of Smoothing Mechanisms of Self-organized Sputter Ripple Patterning on Sapphire," H. Zhou, L. Zhou, R. Headrick, G. Ozaydin, and K. Ludwig Jr. Symposium on Nanoscale Pattern Formation, Materials Research Society Fall Meeting, Boston, MA. November 26 - 30, 2007. Contributed Oral Presentation. 